Running head: EFFECTS OF PRODUCT HOLDERS' SHAPE

\title{
Affordant shapes of product holder influence product evaluation and purchase intention
}

Affordant shapes of product holder influence product evaluation and purchase intention

\author{
Nicoletta Cavazza \\ Veronica Gabrielli \\ University of Modena-Reggio Emilia \\ Italy
}

Authors' note:

Nicoletta Cavazza*, Università di Modena-Reggio Emilia, via Allegri 9, 42100 Reggio Emilia, Phone: +39 0522 523262; fax: +39 0522 523055; E-mail: nicoletta.cavazza@unimore.it

Acknowledgement

We wish to express our gratitude to the company Espo\&Cartotec (Modena-Italy) for providing us with the experimental material, and Cristina Iani for comments on earlier drafts of this manuscript.

\section{Abstract}

Several studies have shown that stocking products on a display stand (vs. on a shelf) favours purchasing. However, little is known about whether the spatial layout of the display stand (i.e., its shape) may influence consumers' evaluation of the product and their purchase intention. The present research aims to investigate the role of the shape of an in-store display as a contextual cue 
potentially able to influence consumers' evaluation of the exposed product and their subsequent purchasing intention. Two experiments were carried out in which we manipulated the shape of the product holder and the brand name as a function of brand awareness. We found that a meaningful shape representing the product induced a more positive product evaluation and indirectly, a greater intention to purchase in respect to shelf, when the product was a little-known brand (Study 1). Furthermore, the strongest effect occurred when the display stand facilitated product affordance in consumers' minds (Study 2). These results confirmed that the ability of the immediate context (i.e., the display stand) to evoke an action with an object (the product) influences the perceiver evaluation and behavioural intention towards the object itself. Theoretical and practical implications of the findings are discussed.

Keywords: volume shape effect, product display, affordance, product evaluation, purchase intention. 


\section{Affordant shapes of product holder influence product evaluation and purchase intention}

Products in supermarkets are often stocked on colored and imaginative display stands. Indeed, this is one of the emerging point-of-purchase activities besides the traditional shelf space allocation or promotional sales. Through display stands, producers and retailers attempt to induce a positive effect in consumers' perceptions, product evaluations, and choices. Their expectations are supported by the evidence that consumer reactions to the product arise from holistic representation, which is built not only on its intrinsic characteristics but also on extrinsic and contextual cues (Bitner, 1992; Bloch, 1995; Castro, Morales, \& Nowlis, 2013; Fischer, Völckner, \& Sattler, 2010; Wilson \& Till, 2011).

Most research on the effects induced by point-of-purchase activities was focused on shelf space elasticity, which is the consumers' response to quantitative and/or qualitative variations in shelf space devoted to a product (e.g., Brown \& Tucker, 1961; Frank \& Mussy, 1970; Curhan, 1972; Bultez \& Naert, 1988; Desmet \& Renaudin, 1998). A recent meta-analysis (Eisend, 2014) highlighted that, although the findings are not always consistent across studies, the mean ratio of additional sales to additional space allocated in retail settings is not at all negligible (.17).

Moreover, the effect is not linear (i.e., consumers are more sensitive to shelf space increase than decrease), and it is negatively related with the necessity of the product. Finally, the shelf space elasticity resulted unaffected by the store size.

Beyond the regular shelf space management, the effects of other visual point-of-purchase activities merit greater attention. In this domain, the influence of in-store display stands on consumer purchasing behaviour is empirically demonstrated and accepted among marketers (e.g., Del Vecchio, Henard, \& Freling, 2006; Sharma, Sivakumaran, \& Marshall, 2010; Yi \& Yoo, 2011). However, this line of research is still limited in two respects. First, the empirical evidence was mostly gathered on the condition of co-occurrence of in-store display and price reduction (Kotzan \& Evanson, 1969; Chevalier, 1975; Gagnon, \& Osterhaus, 1985) or price signal (Inman, McAlister, \& 
Hoyer, 1990). Second, most of the studies carried out so far investigated the mere behavioural effect of placing the product on a display stand without considering how the in-store display affects consumer choice. Does it facilitate impulsive and automatic purchasing or product perception and evaluation? Indeed, little attention has been devoted to the process underlying consumers' behavioural reaction to the mere presence of an in-store display hosting the products.

Recently, Chandon, Hutchinson, Bradlow and Young (2009) expressed this concern, suggesting that the understanding of the cognitive process by which the presence of a display stand interacts with product elements (above all its brands) and leads to the consumer liking and purchasing the product is a worthwhile research direction. In this regard, two studies (Gabrielli \& Cavazza, 2014), conducted on two different grocery products, showed that end-of-aisle-display stands exerted a positive impact on respondents' evaluation of the product and (indirectly) on purchase intention, in comparison with the same product sold without any holder or placed on a shelf. It was also found that the communicative role of the display stand was particularly powerful for unfamiliar product categories and for products with a low level of brand awareness.

The present research springs from these results and aims to investigate the role of the shape of an in-store display as a contextual cue potentially able to influence consumer evaluation of the exposed product and its subsequent purchasing intention.

\section{Judgemental and behavioural effects of the in-store product holder}

Several studies have shown that stocking products on a display stand (vs. on a shelf) favours purchasing. This evidence suggests that the display stand may play the role of a contextual cue, which is also able to significantly affect consumer perception and product judgment, thus orienting the choice. Kotzan and Evanson (1969) showed that the display stand amplified a present-day special characteristic of the product, i.e., temporary price reduction. They reasoned that the presence of a display stand gives salience to the price cut, inducing consumers to focus their attention on the offer, and inclining them to buy this product. In addition, the effectiveness of the in-store display was uncorrelated to the magnitude of the price reduction (Chevalier, 1975). Furthermore, a "price 
cut proxy effect" was observed: the in-store display stand was able to activate in the consumers the idea of a price discount through the mere presence of a promotion signal, even when the product was offered at a regular price (Inman, McAlister, \& Hoyer 1990; Inman \& McAlister, 1993).

Besides the "price cut proxy effect," the display stand makes the exposed product more prominent, increasing the probability of its inclusion in the initial consideration set from which consumers make their choice (Allenby \& Ginter, 1995; Zhang, 2006).

Recent studies (Gabrielli \& Cavazza, 2014) have shown that, even in the absence of any price cut or promotional signal, the display stand becomes a relevant contextual cue when people lack significant previous beliefs about that product. Indeed, the mere presence of the in-store display stand exerted an influence on consumer judgment of the product and purchase intention, only in the case of an unfamiliar brand. This finding confirmed that when consumers see a wellknown brand, they tend to activate a memory-based process (i.e., brand heuristic; Kardes, Posavac, \& Cronley 2004). In this case, the display stands strengthen brand preferences. On the contrary, when consumers see a little-known or a moderately known brand, they formulate their product evaluations integrating product features with contextual information in order to compose their consideration set and their purchase decision. This is in line with Castro et al.'s studies (2013) showing stronger effects of shelf display appearance in condition of unfamiliar (vs. familiar) brand.

Globally, these findings revealed the unexplored matter of consumers' psychological reaction to display stands beside the well-known behavioural effect. However, although it was established that the display stand is able to influence consumers' cognitive processes concerning the product and the decision, which display stand characteristics enhance this effect remains a matter of exploration.

The present studies, which stem from this stream of research, investigate the conditions for the effectiveness of in-store display stands in influencing consumers' cognitive processes and purchase intention. In particular, we explored whether the shape of the display stand may play a 
significant role in making it an effective contextual cue able to exert an influence on consumers' product evaluation and choice.

\section{The effect of object shape}

There is evidence that, in general, people tend to prefer rounded contoured objects over angular contoured ones (Bar \& Neta, 2006). However, when applied to product preferences, some contradictory findings emerge, showing that sometimes angular shaped packaging may be preferred to the rounded option (e.g., Becker, van Rompay, Schifferstein, \& Galetzka, 2011) and that product form preferences may vary over time (Carbon, 2010).

These contradictions suggest that an "objectivist view" of what is liked, as well as research on the ideal form of a product or its package as intrinsic properties of an object, are unsuitable for an understanding of the effect of form on preferences and behaviour. A more interactionist approach is needed, based on the way people and objects relate (Reber, Schwarz, \& Winkielman, 2004). In particular, Reber, Winkielman and Schwarz (1998) stated that aesthetic judgments are grounded in the processing experiences of the perceiver, which are in part a function of stimulus properties. The mere exposure effect (Bornstein, 1989; Zajonc, 1968), for example, testifies that ease of processing can influence a perceiver's evaluative and affective reactions, such as liking a target stimulus. More generally, high processing fluency is reliably associated with more positive evaluations (Reber, Schwarz, \& Winkielman, 2004).

The object familiarity induced by repeated exposure is not the only factor able to facilitate fluent processing and increased liking of the object. Other factors can have a similar effect, even under the condition of a single exposure. Interestingly, for our purpose, Regenberg, Hafner and Semin (2011) were able to demonstrate that physical interactions with the object that are cognitively effortless for the perceiver elicits a positive affective response. They refer to the ecological approach to perception (Gibson, 1979) and rely on the experimental paradigm of the "affordance effect" (Tucker \& Ellis, 1998). Gibson argued that individual perception of the environment involves the direct perception of affordances; for example, people perceive a cup in terms of its 
associated action, such as grabbing it. Thus, in the same way, a consumer does not perceive the product in itself so much as s/he perceives its graspability, liftability, and so on. In Gibson's view, affordances are properties of object layouts, and this is why designers often take into account object shape affordance, which means that the available action can be immediately perceived by the user (Still \& Dark, 2010). A user acting on an affordance does not have to consciously think about what action is available, since it is just apparent, and this effortless process makes the object more attractive than a less affordant one.

In the present research, we wanted to go a step further and investigate whether when keeping constant the shape of the target object (i.e., the product), the shape of its immediate context (i.e., its holder) influences a perceiver's psychological reaction to the object.

To the best of our knowledge, there are no published studies that empirically test whether the spatial layout of the display stand (i.e., its shape) may influence consumer evaluation of the product and their purchase intention. However, the shape of the display stands could be relevant because, as in the case of product packaging (Bloch, 1995), aside from colour and size, shape may attract consumer attention to the display and/or to the exposed product, to orient inferences regarding product attributes and provide sensory pleasure that can be associated with the product via evaluative conditioning.

If we observe display stands in a supermarket, we notice that their shape can take three main forms: a) a regular solid (mostly parallelepipeds); b) an irregular solid (creative shapes unrelated to any real object); c) a meaningful solid (i.e., volumes magnifying real objects). A regular solid is a simple and familiar form in everybody's experience. Facing a regular-shaped display stand may activate a "mere exposure effect" (Zajonc, 1968) creating a high probability of attaching a positive connotation to it. Even if uncorrelated to the specific product held in it, the positive connotation transmitted by a familiar shape might be transferred through evaluative conditioning to the associated product (exposure-induced preference; Stafford, \& Grimes, 2012). In comparison, an irregular solid, i.e., an unexpected shape, could not enjoy the same benefit. This would be a less 
easily processed object than the regularly-shaped display stand. Finally, a display stand representing a meaningful object (e.g., magnifying the product) might benefit both from object familiarity (ease of coding) and the ability to anticipate in the consumers' minds an action with that product. In other words, this shape directly refers to the product such that its "affordance" (Gibson, 1979), and not only an evaluative conditioning process, might favour the product attraction.

\section{Overview and hypotheses}

In the present research, we conducted two studies to test the effect exerted by the 3-D shape of the display stand holding a product on consumers' evaluation of that product and its purchase intention, applied to two very different convenience goods: a liquid cleaner in Study 1, and an instant chocolate pudding mix in Study 2. Detergent and chocolate have often been considered prototypical examples of utilitarian and hedonic product categories, respectively (for a review, see Alba \& Williams, 2013). Both products were articulated in three brands. We considered product evaluation as a potential mediator of the effect of product display on purchase intention.

In line with previous studies cited above, we expected to find that:

Hp1: In general, when no sales promotion signalled by the display stand is at stake, consumers should appreciate the product more when it is stocked on a coloured and communicative display stand rather than when it is on a shelf. However, the influence exerted by the display stand on product evaluation should be a function of its shape. In particular, we inferred that:

Hp1a: when the display stand shape is affordant because it refers to the hosted object (i.e., it magnifies the product), we should observe the strongest positive influence on the product evaluation.

Hp1b: When the shape is not related to the hold object but is easy to process because of its familiarity (i.e., display stand with a regular volume shape), it should exert a moderate influence due to a mere exposure effect.

Hp1c: Finally, we expected the weakest effect in the case of the irregularly-shaped display stand because of the relatively effortful processing it requires. 
Hp2: In line with previous studies showing that the display stand indirectly influences the purchase intention through product evaluation, we should find an indirect effect of display stand shapes on purchase intention through product evaluation.

Given that consumers' openness to resort to situational stimulus is likely when they cannot rely on consolidated beliefs (e.g., the brand heuristics; Kardes et al. 2004), we expected that:

Hp3: the display stand shape influence on purchase intention through product evaluation would be moderated by brand awareness: a more evident effect is expected when stocking a littleknown brand than a moderately known brand or a well-known brand.

\section{Study 1}

\section{Method}

Participants. A convenience sample of 191 Italian people voluntarily participated in the research. The recruitment was carried out by 33 participants in a marketing professional training course among their relatives, friends, and acquaintances as part of a course assignment. The mean age of the sample was $44.68(S D=12.40)$, and 146 were women. Participants were randomly assigned to the experimental conditions in a 3 (brand awareness: low, medium, high) $\times 4$ (product holder: shelf; display stand with a regular shape, display stand with an irregular shape; display stand with the shape of a big liquid cleaner packaging) factorial between-participants design.

Materials and procedure. Participants were told they were taking part in a large market study on liquid cleaner. They looked at a fictitious image depicting nine liquid cleaner bottle facings of a specific existing brand, stored on an end-of-aisle support according to four conditions: 1) shelf in isolation (control condition), 2) display stand with a regular shape (i.e., a parallelepiped), 3) display stand with an irregular shape, and 4) display stand reproducing the same bottle of liquid cleaner (images available from the authors on request).

Participants were then asked to complete a brief questionnaire in which they had to evaluate the product and express their purchase intention. Some demographic items (i.e., sex, age, and 
number of family members) were also included, as well as some questions about shopping habits as potential control variables. Since gender and whether or not a respondent was responsible for family purchases did not affect our dependent variables or interact with our independent variables, we do not discuss them further.

When they had completed the questionnaire, participants were thanked and debriefed, and the actual scientific research goal was revealed.

\section{Independent variable}

Product holder. As stated, we had a control condition: one image with the product stocked on the shelf. The experimental conditions were operationalized by the images of the same product stocked on an end-of-aisle display stand (irregular vs. regular vs. meaningful). For each brand, the display stands had the same dominant colours (white and blue) and reported the brand logo and payoff.

\section{Moderator}

Brand awareness. We selected three liquid cleaner brands currently and widely available in Italian supermarkets, which met the following criteria: they had to have the same dominant colours, comparable prices, and the same shape and volume but have different brand salience. As for the last criterion, we did include an item in the questionnaire checking for awareness level (i.e., "How well do you know this brand of cleaner?"). A one-way analysis of variance (ANOVA) on answers (range $1=$ "I do not know it at all" - 10 "I know it very well") confirmed our selection: the first brand received a mean of $7.78(S D=1.99)$; the second brand had an average awareness level of $6.30(S D$ $=2.74)$; and the third brand received a mean of $3.48(S D=2.60), F(2,179)=49.94, p<.001$.

\section{Dependent measures}

Product evaluation. We measured product evaluation by means of four items. We asked participants to rate the product from 1 to 10 (this range of evaluation is very familiar to Italian people because it is the scale used for school marks). Three other items requested the same 10-point 
score on three product dimensions: quality, attractiveness, and look of the product. Responses were averaged into a single evaluation index $(\alpha=.90)$.

Purchase intention. We measured purchase intention with one item phrased as follows: "The next time you purchase liquid cleaner, how likely are you to purchase this product?" Participants had to choose from four possible answers: "I will definitely not purchase it," "Not very likely," "Quite likely,” or "I will definitely purchase it.” A score of purchase intention was assigned, ranging from 1 "no purchase intention" to 4 "strong purchase intention."

\section{Results}

Table 1 reports descriptive statistics for our measures.

Display stand shape influence on product evaluation and purchase intention.

Two univariate analyses of variance (ANOVA) with type of product holder (shelf vs. irregular-shaped vs. regular-shaped vs. meaningful-shaped display stand) and brand awareness (low, medium, high) as independent factors were performed on product evaluation and purchase intention (Table 2). The brand awareness, $F(2,179)=39.73, p<.001, \eta^{2}=.31$, and the product holder shape main effects, $F(3,179)=4.05 p=.008, \eta^{2}=.06$, emerged on product evaluation. Simple contrast tests revealed that the product elicited the most positive evaluation when it was a well-known brand in respect to when it was a moderately known brand $(p<.001)$ or a little-known brand $(p<.001)$. More interestingly, in line with Hp1c, the same test for the display stand conditions showed that the irregular-shaped display did not differ from the shelf in influencing product evaluation $(p=.11)$, whereas the regularly-shaped $(p=.04)$ and the meaningful-shaped ones $(p<.001)$ were more effective than the shelf in positively influencing product evaluation (Hp1a; Hp1b). The interaction between the two factors did not reach significance, $F(6,179)=.55, p$ $=.77, \eta^{2}=.02$.

In order to test the potentially direct influence of display shape on purchase intention, the same analysis of variance was run on this dependent variable. The analysis yielded the main effects of both the factors, $F_{\text {brand }}(2,178)=16.08, p<.001, \eta^{2}=.15, F_{\text {display shape }}(3,178)=3.02, p=.03, \eta^{2}=$ 
.049 , and they were qualified by the interaction between the factors, $F(6,178)=2.64, p=.02, \eta^{2}=$ .08. The inspection of the simple effects showed that in the condition of a well-known brand, the meaningful-shaped display elicited a stronger intention to buy the product in respect to the regularly-shaped one (LSD post-hoc test, $p=.003$ ); in the condition of a moderately known brand, the shape of the display did not influence purchase intention; and in the condition of a little-known brand, all three kinds of display stands were effective in inducing a higher purchase intention in respect to the shelf $\left(p_{\text {irregular }}=.044 ; p_{\text {regular }}=.003 ; p_{\text {meaningful }}=.024\right)$ but they did not differ from each other.

To sum up, the regularly- and the meaningful-shaped display stands, irrespective of the product brand awareness, induced a better product evaluation in respect to both the shelf and the irregularly-shaped display. However, only when the product was a little-known brand, did the three product holders, more than the shelf, directly influence the intention to buy it.

\section{Indirect effects of display stand shapes on purchase intention}

In order to test $\mathrm{Hp} 2$, we tested a model for each brand separately in which product evaluation plays a mediational role between product display and purchase intention using a bootstrapping approach (Preacher \& Hayes, 2004). This was done by comparing the effect of each display stand (irregular, regular or meaningful), coded as dummy variables, with the control condition (shelf $=0$ ), and we tested the mediated or indirect effect, as depicted in Figure 1, using MEDIATE, the SPSS Macro provided by Hayes (2013), setting 5,000 bootstrapped samples.

Table 3, reporting the coefficients issued from the final regression including all predictors on purchase intention, shows that only in the condition of the little-known brand did the display stand with a meaningful shape indirectly influence purchase intention via product evaluation.

\section{Discussion}

In synthesis, we found that: a) the irregularly-shaped display directly influenced the intention to buy the product when it was a little-known brand, without the mediation of its positive evaluation; b) the regularly-shaped display stand was more successful than the shelf in influencing 
the product evaluation in all brand awareness conditions but not the intention to buy it (except the direct effect in the case of the little-known brand); and c) only the meaningful-shaped display increased the positive evaluation of the product irrespective of the brand awareness, and, in the condition of the little-known brand, its effect reached the purchase intention via the mediation of the product evaluation.

These results suggest, first of all, that the ability of the in-store display stand to be an actual informational cue is related mainly to its meaningfulness. The display stand magnifying the packaging, with its easily-visible handle, made the product affordance salient, and plausibly, the mere viewing of the product activates the motor programs necessary to interact with the seen object (Bub, Masson, \& Cree, 2008).

The second relevant finding we draw from this first study is that the display stand influence was moderated by the brand awareness, and, in particular, consumers showed a reliance on the contextual cue mainly in the condition involving a little-known brand. In the case of a familiar brand, consumers tended to ground their evaluation on the "brand heuristics" rather than on any other contextual information. Thus, as expected (Hp3), the display stand exhibited its informational role within the decisional process mainly when participants were not able to anchor their judgment and choice to a memory-based process (brand heuristic) but rather when they engaged in a stimulusbased process.

Even if the findings of the present study confirmed the interpretation in terms of product affordance put forward by the meaningful display stand shape, we cannot exclude that meaningfulness of the product holder per se (excluding product affordance) could influence consumer evaluation and purchase intention, so that any other meaningful-shaped display (e.g., one representing a Christmas tree) could induce the same effects. In order to disentangle these alternative interpretations, in Study 2, we compared the effect of different meaningful - more or less affordant - shapes of a display stand. We also wanted to replicate the results using another product category. 


\section{Study 2}

The second study aimed at inspecting what meaning should evoke the 3-D shape of the display stand in order to improve the product evaluation and to enhance the purchase intention. In particular, we wanted to test whether making product affordance salient is actually a way of inducing positive product evaluation or whether the effect observed in Study 1 was simply due to the ability of the display stand to evoke a meaning. Thus, we compared the effect induced in consumer evaluation and purchase intention by three types of display stands differing only in their shape (more or less affordant, see details below) with the shelf (control condition) across three brands.

Furthermore, in respect to Study 1, we tested this effect on a different kind of product (i.e., a food product of high hedonic value), allowing us to distinguish between shapes evoking just the product vs. the consumption occasion vs. the action with the product (affordance).

\section{Method}

Participants. A convenience sample of 261 people voluntarily participated in this study ${ }^{1}$. Five university students recruited the participants and carried out the experiment as part of a course assignment in brand management at a medium size Italian university. Students acting as research assistants were carefully instructed on the experimental procedure. Each student was required to recruit at least 50 participants distributed equally among the modalities of the independent variables (brand and product display). The mean age of the sample was $46.28(S D=14.86)$, and 184 were women. As in our previous study, participants were randomly assigned to the experimental conditions in a 3 (brand awareness: high; medium; low) $\times 4$ (product display: shelf; display stand evoking the product; display stand evoking the consumption occasion, i.e., Christmas; display stand evoking the action with the product) factorial between-participants design.

Materials and procedure. The procedure was identical to that of Study 1 but participants saw one fictitious image depicting several dozen instant chocolate pudding mix packages simply 
stocked on an end-of-aisle shelf (control condition) or stocked on an end-of-aisle display stand varying according to three experimental conditions (see description below).

Participants were then asked to answer the questionnaire in which they had to formulate their evaluation of the product and their purchase intention. Data for the present study were gathered along with data for other research purposes. The same demographic items (i.e., sex, age, and number of family members) were included, as well as the questions about shopping habits as potential control variables. In this case too, gender and responsibility for family shopping did not affect our dependent variables nor interacted with our independent variables.

When they had completed the questionnaire, participants were thanked and debriefed, and the actual scientific research goal was revealed.

\section{Independent variable}

Product display. For this study, we had a first set of three images (one for each of the three brands) with products stocked on the shelf; a second set of images with the same products stocked on a display stand representing a big chocolate pudding (evocation of internal meaning); a third set showing the same products on a display stand with the shape of a Christmas tree (evocation of external meaning, i.e., the consumption occasion); and in a fourth experimental condition, the products were on a display stand with the shape of a big chocolate pudding on a dish with a little spoon. This latter condition was intended to promote the perceptual affordance of the product. Obviously, the big chocolate pudding too affords the action of eating but we reasoned that the presence of the little spoon made this action more salient. Thus, since affordance is a graded propriety (Greeno, 1994), we can conceive of this experimental condition as higher in affordance than the previous one.

All of the display stands had the same dominant colours (blue and brown) and represented the brand logo and the pay-off.

\section{Moderator}


Brand awareness. We selected three brands of instant chocolate pudding mix currently and widely available in Italian supermarkets, using the same selection criteria as in Study 1: they had to have the same dominant colours (brown and blue) and comparable prices but different salience and so different likelihood of being known. As regards the last criterion, the one-way analysis of variance (ANOVA) on self-reported product knowledge (range 1 = "I do not know it at all" - 10 "I know it very well") confirmed our selection: the "well-known" brand received a mean of 7.49 (SD $=2.64)$; the "moderately known" brand had an average knowledge level of $6.49(S D=2.34)$; and the "little-known" brand had a mean of $4.84(S D=2.97), F(2,258)=22.04, p<.001$.

\section{Dependent measures}

Product evaluation. The same items as in Study 1 were included in the questionnaire, and responses were averaged into a single product evaluation index $(\alpha=.87)$.

Purchase intention. We measured brand purchase intention with one item phrased as follows: "Imagine you decided to purchase a ready-to-make chocolate pudding, how likely are you to purchase this brand product?" Participants had to choose from four possible answers: "I will definitely not purchase it," "Not very likely," "Quite likely," or "I will definitely purchase it." A score of purchase intention was assigned, ranging from 1 "no purchase intention" to 4 "strong purchase intention."

\section{Results}

Table 4 reports descriptive statistics for our measures.

\section{Display stand shape influence on product evaluation and purchase intention}

Two univariate analyses of variance (ANOVA) with type of product holder (shelf vs. internal meaningful-shaped vs. external meaningful-shaped vs. affordant-shaped display stand) and brand awareness (low, medium, high) as independent factors were performed on product evaluation and purchase intention (Table 5). The first involving evaluation showed the main effect of brand awareness, $F(2,249)=4.02, p=.02, \eta^{2}=.03$, and the interaction between the two factors, $F(6,249)$ $=2.69, p=.015, \eta^{2}=.06$. The inspection of the simple effects revealed that the interaction issued 
from the well-known and the little-known brand; as in the former, the product on the shelf (control condition) was evaluated more positively in respect to when it was stocked on an external meaningful-shaped display stand $(p=.003)$. On the other hand, in the latter case, the affordantshaped display stands $(p=.049)$ induced a more positive product evaluation than did the shelf.

The second ANOVA revealed that our independent variables failed to directly influence the participants' purchase intention.

Indirect effects of display stand shapes on purchase intention

To sum up, ANOVA results suggest that the effect of the display stands in inducing a positive evaluation of the product decreased as a function of brand awareness, since for a wellknown brand, the shelf provoked a more positive evaluation of the product in respect to the display stands (i.e., the external meaningful-shaped). As regards the moderately known brand, there were no differences due to the product holder, and only in the condition of the little-known brand, was the display stand with the most affordant shape more effective than the shelf. None of the product holders directly influenced the participants' intention to buy it. Thus, we proceeded to test whether affordant-shaped display influenced the purchase intention indirectly through product evaluation when holding a little-known brand product.

We performed the same analysis as in Study 1 selectively for the little-known brand. The regression including the dummy-coded product holder (affordant-shaped display $=1$; shelf $=0$ ) and the product evaluation as predictors confirmed that indeed the display stand with a shape promoting the affordance appraisal of the product did indirectly influence purchase intention of the littleknown brand via product evaluation (indirect effect $=.35 ; S E=.18 ; L L C I=.02 ; U L C I=.73$ ).

\section{Discussion}

In the second study, we addressed why the display stand magnifying the product shape was the most effective in inducing positive product evaluation and (indirectly) purchase intention. We reasoned that the display stand could be used as a significant informational cue on behalf of the consumer's decisional process because of its ease of process and, in particular, when this ease was 
due to the ability to evoke the action with the product (affordance). The results of the second study confirmed this hypothesis, as the only display stand able to significantly affect participants' evaluation, and thus their intention to buy, was the one depicting the food product on a dish beside a spoon. The meaningfulness of the display stand shape merely tied to the product's intrinsic characteristics or external meanings, such as the occasions suitable for this product consumption, were not enough to influence the participants' evaluation and purchase intention.

Although consistent with our hypothesis, our results could be interpreted as due to a higher hedonic value elicited by the affordant-shaped display stand in respect to the other product holders. Because the pudding would be purchased for its hedonic value, it might be that the display stand depicting the pudding ready to eat with the spoon visual included is the only one able to stimulate hedonic pleasure anticipation. In this case, the spoon would not necessarily be an informational cue but a visual cue associated to the hedonic pleasure derived from purchasing and eating the pudding. In order to rule out this alternative explanation, we took into consideration two items embedded within the product evaluation scale in the questionnaire, and referring to the emotional activation induced by the product ("how much does the seen product make you feel pleasure/satisfaction?" answer range 1-10). In both cases, the means were not significantly different from each other as a function of the display stand conditions: Global $M_{\text {pleasure }}=6.01, S D=2.40, F_{\text {pleasure }}(3,257)=1.05, p$ $=.37$; global $M_{\text {satisfaction }}=5.28, S D=2.60, F_{\text {satisfaction }}(3,257)=.17, p=.92$. These tests confirmed that our interpretation in terms of affordance power of influence is the most plausible. $^{2}$

Again, when respondents saw a product with an already known logo on a display stand, they made their choice based on their attitude towards this brand. The contribution of the display stands in this situation, whatever their shape, was merely to show the brand and thus to facilitate the activation of a brand heuristics. In comparison, when consumers faced an unknown brand, they had less chance of making a choice unless they relied on contextual stimuli, and then the effect of an affordant shape came into view. Thus, the product display was interpreted by consumers as an 
authentic informational cue able to inform their decisional process affecting their judgements and thus their intention to buy.

\section{General discussion}

The main aim of this paper was to investigate whether the shape of an end-of-aisle display stand can influence consumers' evaluation of the product held and intention to buy it. The two studies together show that the product holder, a coloured and 3-D-shaped object, placed outside the regular aisle, may affect consumers' evaluation of the product and, indirectly, their purchase intention, even when it is not associated with a price reduction. This is in line with previous studies showing that ad hoc physical supports devoted to host the product induce cognitive processes in the consumers, shaping their evaluations and thus their choice (Gabrielli \& Cavazza, 2014).

The present research showed that the two conditions needed to observe this effect are: a) the product hosted is branded by a company consumers do not know so well; and b) the display stand has an affordant meaningful shape evoking the action with the product itself.

The moderation effect of brand awareness confirmed that consumers tend to utilize a memory-based decisional process when they face a brand they already know. In this case, the role of the in-store display is merely to highlight this information, enabling consumers to rely on it for their choice. On the contrary, when consumers do not have previous beliefs about the presented brand or product, they look for other significant stimuli available within the decisional context in order to formulate their evaluations, and thus their choice. In this case, the in-store display stand is likely to favour a stimulus-based process.

More importantly, to our knowledge, this is the first direct evidence that the ability of the immediate context (i.e., the display stand) to evoke an action with an object (the product) influences the perceiver evaluation and behavioural intention towards the object itself. Our confidence in the robustness of these results is enhanced by the consistency across two different convenience goods (i.e., a utilitarian and a hedonic product). 
Despite the converging evidence, at least some limitations of the present studies must be acknowledged. First, we asked our participants to formulate an absolute evaluation of the product outside a comparative context, since our simulation was made through the image of an end-of-isle display stand. However, placing the product on a holder that separates the product from competing brands is a solution often employed in real-existing point of sales and supermarkets. In order to increase the generalizability of our findings, it would be useful to analyse the consumer decisional process through a comparative task, as single vs. comparative judgments are usually formulated in a different way (Kardes, Posavac, \& Cronley, 2004; Sanbonmatsu, Kardes, Posavac, \& Houghton, 1997).

The second limitation is that we carried out the second experiment much earlier than winter, and therefore, the effect of the display stand shape evoking Christmas might be underestimated. We chose this form because the scope of a Christmas stimulus within point of sale is mostly related to its impact on store image and atmosphere, rather than the single product evaluation.

Notwithstanding these limitations, we believe that the present results contribute to the consumer psychology literature as they reveal that, when a brand is not really well-known, consumers evaluate the product taking into particular account situational cues, including those conveyed by the product holder. In this process, they are influenced most notably by the way in which the context makes the product affordance available. Our findings are in line with Gibson's framework about how the environment supports cognitive activity. Indeed, the display stand favouring the product affordance, for the consumer, makes the action with the product salient without mental effort. This is likely to be at the basis of the communicative efficacy of such a display stand. Future research must provide a more direct test of this interpretative hypothesis (for example, manipulating consumers' cognitive ability or need for accuracy, and directly measuring perceiver product processing and the potential mediational role of the display liking).

Discovering the processes underlying consumers' behavioural reactions to this kind of communicative in-store option is particularly interesting for consumer behaviour researchers and 
for practitioners who, in a real-context, have to decide on investment in this kind of communicative supports. In particular, retailers who host many in-store display stands in their point of sale and manufacturers who want to sort out their product from the shelf through these holders might be interested in three focus-points which emerged in this research.

First, the evidence that the effect of a display stand on behaviour is mediated by product evaluation reveals a new interpretative perspective in respect to the traditional impulse buying behaviour perspective (Sharma, Sivakumaran and Marshall 2010). The mediating role of product evaluation suggests that a more resistant and deep effect could be exerted by the holder than a mere impulse buying behaviour.

Second, for retailers and manufacturers, this finding is interesting as they tend to adopt display stands as a low-margin activity; they often associate relevant investment in order to project and build display stands and the product offer at a special price. Our findings corroborate the evidence that in-store display stand impact is observable even in the absence of any price reduction.

Third, our findings enable retailers and manufacturers who are involved in the aesthetic design of display stands in choosing the appropriate shape. Indeed, we usually observe imaginative and surprising product holders, appealing in terms of colours, dimensions, graphics, and shapes. The suggestions from our findings seem contrary to those solutions unrelated to the product or, if meaningful, related to consumption situations or seasonal pertinence.

Our results suggest focusing attention on the interaction between brand awareness and display solution. That is, for products with high brand awareness, it may not be necessary to invest substantial creative efforts to realize fantastic solutions. In this respect, the display stand shape does not matter and to make a brand logo as evident as possible could be enough. On the other hand, when designing a display stand for a product with low brand awareness, paying attention to the appearance and choosing a shape able to evoke the product and the action with it (i.e., an affordant shape) could be worthwhile. 


\section{References}

Alba, J. W., \& Williams, E. F. (2013). Pleasure principles: A review of research on hedonic consumption. Journal of Consumer Psychology, 23, 2-18. http://dx.doi.org/10.1016/j.jcps.2012.07.003

Allenby, G. M., \& Ginter, J.L. (1995). The effects of in-store display and feature advertising on consideration sets. International Journal of Research in Marketing, 12, 67-80.

Bar, M. \& Neta, M. (2006). Humans prefer curved visual objects. Psychological Science, 17, 645648. doi: 10.1111/j.1467-9280.2006.01759.

Becker, L., van Rompay, T.J.L., Schifferstein, H.N.J., \& Galetzka, M. (2011). Tough package, strong taste: The influence of packaging design on taste impressions and product evaluations. Food Quality and Preference, 22, 17-23. doi: 10.1016/j.foodqual.2010.06.007

Bitner, M.J. (1992). Servicescapes: The impact of physical surroundings on customers and employees, Journal of Marketing, 56 (2), 57-71. http://www.jstor.org/stable/1252042.

Bloch, P.H. (1995). Seeking the ideal form: Product design and consumer response, Journal of Marketing, 59, 16-29. doi: 10.2307/1252116.

Bornstein, R.F. (1989). Exposure and affect: Overview and meta-analysis of research 1968-1987. Psychological Bulletin, 106, 265-289. doi: 10.1037/0033-2909.106.2.265.

Brown, W.M. \& Tucker, W.T. (1961). The marketing center: Vanishing shelf space. Atlanta Economic Review, 11(10), 9-13.

Bub, D.N., Masson, M.E.J., \& Cree, G.S. (2008). Evocation of functional and volumetric gestural knowledge by objects and words. Cognition, 106, 27-58. http://dx.doi.org/10.1016/j.cognition.2006.12.010.

Bultez, A. \& Naert, P. (1988). SH.ARP. Shelf allocation for retailers' profit. Marketing Science, 7(3), 211-231. Permalink: http://dx.doi.org/10.1287/mksc.7.3.211

Carbon, C.C. (2010). The cycle of preference: long-term dynamics of aesthetic appreciation, Acta Psychologica. 134, 233-244. doi:10.1016/j.actpsy.2010.02.004. 
Chandon, P., Hutchinson, J.W., Bradlow, E.T., \& Young S.H. (2009). Does in-store marketing work? Effects of the number and position of shelf facings on brand attention and evaluation at the point of purchase. Journal of Marketing, 73, 1-17.

http://dx.doi.org/10.2139/ssrn.1406506.

Castro, I.A., Morales, A.C., \& Nowlis, S.M. (2013). The influence of disorganized shelf displays and limited product quantity on consumer purchase. Journal of Marketing, 77, 118-133. doi: http://dx.doi.org/10.1509/jm.11.0495

Chevalier, M. (1975). Increase in sales due to in-store display. Journal of Retailing, 51, 65-72. Accession number 4999995.

Curhan, R.C. (1972). The Relationship between shelf space and unit sales in supermarkets. Journal of Marketing Research, 9, 406-412. Article Stable URL: http://www.jstor.org/stable/3149304

Del Vecchio, D., Henard, D.H., \& Freling, T.H. (2006). The effect of sales promotion on postpromotion brand preference: a meta-analysis. Journal of Retailing, 86 (3), 203-213. doi:10.1016/j.jretai.2005.10.001.

Desmet, P. \& Renaudin, V. (1998). Estimation of product category sales responsiveness to allocated shelf space. International Journal ofResearch in Marketing, 15(5), 443-457.

Eisend, M. (2014). Shelf space elasticity: a meta analysis. Journal of Retailing, 90(2), 168-181.

Fischer, M., Völckner F., \& Sattler, H. (2010). How important are brands? A cross-category, crosscountry study. Journal of Marketing Research, 47, 823-839. doi: 10.1509/jmkr.47.5.823.

Frank, R. E., \& Massy, W. F. (1970). Shelf position and space effects on sales. Journal of Marketing Research, 7, 59-66. Article Stable URL: http://www.jstor.org/stable/3149508

Gabrielli, V. \& Cavazza, N. (2014). The influence of in-store product holders on orientation toward the product and on purchase intention. The International Review of Retail, Distribution and Consumer Research, 24, 311-327. doi: 10.1080/09593969.2013.862507 
Gagnon, J.P. \& Osterhaus, J.T. (1985). Effectiveness of floor displays on the sales of retail products. Research Note of Journal of Retailing, 61, 104-116. Accession number 4667984.

Gibson J.J. (1979). The ecological approach to visual perception. Boston, MA: Houghton Mifflin. Greeno, J.G. (1994). Gibson's affordances. Psychological Review, 101, 336-342. doi: 10.1037/0033295X.101.2.336

Hayes, A.F. (2013). Introduction to mediation, moderation, and conditional process analysis: A regression based approach. New York: The Guilford Press.

Inman, J.J. \& McAlister L. (1993). A retailer promotion policy model considering promotion signal sensitivity. Marketing Science, 12 (4), 339-356. doi: 10.1287/mksc.12.4.339.

Inman, J.J., McAlister, L., \& Hoyer, W.D. (1990). Promotion signal: Proxy for a price cut?. Journal of Consumer Research 17(June),74-81. doi: 0093-5301/90/I701-O007

Kardes, F.R., Posavac, S.S., \& Cronley, M.L. (2004). Consumer inference: A review of processes, bases, and judgment contexts, Journal of Consumer Psychology, 14, 230-256. doi: 10.1207/s15327663jcp1403_6.

Kotzan, J.A. \& Evanson, R.A., (1969). Responsiveness of drug store sales to shelf space allocations. Journal of Marketing Research, 6, 465-469. http://www.jstor.org/stable/3150084 10.2307/3150084.

Preacher, K.J. \& Hayes, A.F. (2004). SPSS and SAS procedures for estimating indirect effects in simple mediation models. Behavior Research Methods, Instruments and Computers, 36, 717-731. doi:10.3758/BF03206553.

Reber, R., Schwarz, N., \& Winkielman, P. (2004). Processing fluency and aesthetic pleasure: Is beauty in the perceiver's processing experience? Personality and Social Psychology Review, 8, 364-382.doi: 10.1207/s15327957pspr0804_3.

Reber, R., Winkielman, P., \& Schwarz, N. (1998). Effects of perceptual fluency on affective judgments. Psychological Science, 9, 45-48. doi:10.1111/1467-9280.00008. 
Regenberg, N.F.E., Hafner, M., \& Semin, G.R. (2011). The Groove move. Action affordances produce fluency and positive affect. Experimental Psychology, 59, 30-37. doi: 10.1027/1618-3169/a000122.

Sanbonmatsu, D.M., Kardes, F.R., Posavac, S.S., \& Houghton, D. C. (1997). Contextual influences on judgment based on limited information. Organizational Behavior and Human Decision Processes, 69(3), 251-264. doi: 10.1006/obhd.1997.2686

Sharma, P., Sivakumaran, B., \& Marshall, R. (2010). Exploring impulse buying and variety seeking by retail shoppers: towards a common conceptual framework. Journal of Marketing Management, 26, 473-494. doi:10.1080/02672570903485097.

Stafford, T. \& Grimes, A. (2012). Memory enhances the mere exposure effect. Psychology \& Marketing, 29, 995-1003. doi: 10.1002/mar.20581.

Tucker, M. \& Ellis, R. (1998). On the relations between seen objects and components of potential actions. Journal of Experimental Psychology: Human Perception and Performance, 24, 830846. doi: $10.1037 / 0096-1523.24 .3 .830$

Still, J.D. \& Dark, V.J. (2010). Examining working memory load and congruency effects on affordances and conventions. International Journal of Human-Computer Studies, 68, 561571. http://dx.doi.org/10.1016/j.ijhcs.2010.03.003

Wilson, R.T. \& Till, B.D. (2011). Effects of outdoor advertising: does location matter? Psychology and Marketing, 28, 909-933. doi: 10.1002/mar.20418.

Yi, Y. \& Yoo, J. (2011). The long-term effects of sales promotions on brand attitude across monetary and non-monetary promotions. Psychology \& Marketing, 28, 879-896. doi: 10.1002/mar.20416.

Zajonc, R. B. (1968). Attitudinal effects of mere exposure. Journal of Personality and Social Psychology, 9, 1-27. doi:10.1037/h0025848. 
Zhang, J. (2006). An integrated choice model incorporating alternative mechanisms for consumers' reactions to in-store display and feature advertising. Marketing Science, 25(3), 278-290. doi $10.1287 / \mathrm{mksc} .1050 .0170$. 


\section{Footnote}

1. None of the participants took part to both the studies here presented. The two samples are completely independent from each other.

2. We wish to thank an anonymous reviewer for this suggestion. 
Table 1

Descriptive statistics for measures and intercorrelations (Study 1).

\begin{tabular}{lccccc}
\hline & $M$ & $S D$ & Min-Max & \multicolumn{2}{c}{ Correlations } \\
\hline 1. Brand awareness & 5.84 & 3.04 & $1-10$ & & \\
\hline 2. Product evaluation & 6.15 & 1.81 & $1-10$ & $+.65^{* *}$ & \\
\hline 3. Purchase intention & 2.39 & .81 & $1-4$ & $+.40^{* *}$ & $+.54^{* *}$ \\
\hline
\end{tabular}

Note: **Correlation is significant at the .001 level. 
Table 2.

Product evaluation and purchase intention (mean and standard deviation) as a function of brand awareness and product holder (Study 1).

\begin{tabular}{lcccccc}
\hline & \multicolumn{3}{c}{$\begin{array}{c}\text { Product evaluation } \\
\text { (range 1-10) }\end{array}$} & \multicolumn{3}{c}{$\begin{array}{c}\text { Purchase intention } \\
\text { (range 1-4) }\end{array}$} \\
& $\begin{array}{l}\text { Well- } \\
\text { known } \\
\text { brand }\end{array}$ & $\begin{array}{l}\text { Moderately } \\
\text { known } \\
\text { brand }\end{array}$ & $\begin{array}{l}\text { Little- } \\
\text { known } \\
\text { brand }\end{array}$ & $\begin{array}{l}\text { Well- } \\
\text { known } \\
\text { brand }\end{array}$ & $\begin{array}{l}\text { Moderately } \\
\text { known } \\
\text { brand }\end{array}$ & $\begin{array}{l}\text { Little- } \\
\text { known } \\
\text { brand }\end{array}$ \\
\hline Shelf & 6.80 & 5.98 & 4.03 & 2.75 & 2.75 & 1.56 \\
& $(1.49)$ & $(1.67)$ & $(1.91)$ & $(.86)$ & $(.68)$ & $(.73)$ \\
Irregular-shaped display & 7.35 & 6.06 & 4.85 & 2.94 & 2.40 & 2.06 \\
stand & $(1.05)$ & $(.90)$ & $(1.45)$ & $(.83)$ & $(.51)$ & $(.68)$ \\
Regular-shaped display & 7.30 & 6.10 & 5.33 & 2.20 & 2.38 & 2.33 \\
stand & $(1.89)$ & $(1.18)$ & $(1.93)$ & $(.94)$ & $(.81)$ & $(.72)$ \\
Meaningful-shaped display & 7.62 & 6.98 & 5.37 & 3.13 & 2.56 & 2.13 \\
stand & $(1.20)$ & $(1.35)$ & $(1.66)$ & $(.62)$ & $(.63)$ & $(.62)$ \\
\hline
\end{tabular}


Table 3.

Summary of the indirect effects of display stand shape on purchase intention via product evaluation as a function of brand awareness (Study 1).

\begin{tabular}{|c|c|c|c|c|c|c|c|}
\hline & \multicolumn{7}{|c|}{ Well-known brand $\left(R^{2}=.28 p<.001\right)$} \\
\hline & $b$ & $S E$ & $t$ & $p$ & $\begin{array}{c}\text { Indirect } \\
\text { effect }\end{array}$ & LLCI & ULCI \\
\hline Constant & 1.23 & .50 & 2.44 & .017 & & & \\
\hline Product & .22 & .07 & 3.26 & .002 & & & \\
\hline evaluation & & & & & & & \\
\hline (mediator) & & & & & & & \\
\hline Irregular & .06 & .26 & .25 & .80 & .12 & -.07 & .39 \\
\hline Regular & -.66 & .27 & -2.41 & .019 & .11 & -.16 & .53 \\
\hline Meaningful & .18 & .27 & .69 & .49 & .18 & -.02 & .52 \\
\hline
\end{tabular}

Moderately known brand $\left(R^{2}=.19 p<.05\right)$

\begin{tabular}{|c|c|c|c|c|c|c|c|}
\hline Constant & .91 & .43 & 2.14 & .036 & & & \\
\hline Product & .22 & .06 & 3.40 & .001 & & & \\
\hline \multicolumn{8}{|l|}{ evaluation } \\
\hline \multicolumn{8}{|l|}{ (mediator) } \\
\hline Irregular & .14 & .24 & .62 & .540 & .00 & -.23 & .22 \\
\hline Regular & .16 & .23 & .68 & .498 & .03 & -.21 & .21 \\
\hline Meaningful & .09 & .24 & .37 & .715 & .22 & -.01 & .53 \\
\hline
\end{tabular}

Little-known brand $\left(R^{2}=.30 p<.001\right)$

\begin{tabular}{lllll}
\hline Constant & .89 & .25 & 3.63 & .000 \\
Product & .17 & .05 & 3.54 & .001 \\
evaluation & & & & \\
(mediator) & & & &
\end{tabular}




\begin{tabular}{lccccccc} 
Irregular & .36 & .22 & 1.61 & .112 & .13 & -.05 & .41 \\
Regular & .55 & .23 & 2.37 & .021 & .22 & -.01 & .54 \\
Meaningful & .34 & .23 & 1.47 & .148 & .22 & .02 & .49 \\
\hline
\end{tabular}


Table 4

Descriptive statistics for measures, and intercorrelations (Study 2).

\begin{tabular}{lccccc}
\hline & $M$ & $S D$ & Min-Max & \multicolumn{2}{c}{ Correlations } \\
\hline 1. Brand awareness & & & & 1 & 2 \\
\hline 2. Product evaluation & 6.28 & 2.87 & $1-10$ & & \\
\hline 3. Purchase intention & 6.21 & 1.75 & $1-10$ & $.46^{* *}$ & \\
\hline
\end{tabular}

Note: **. Correlation is significant at the .001 level. 
Table 5.

Product evaluation and purchase intention (mean and standard deviation) as a function of brand awareness and product holder (Study 2).

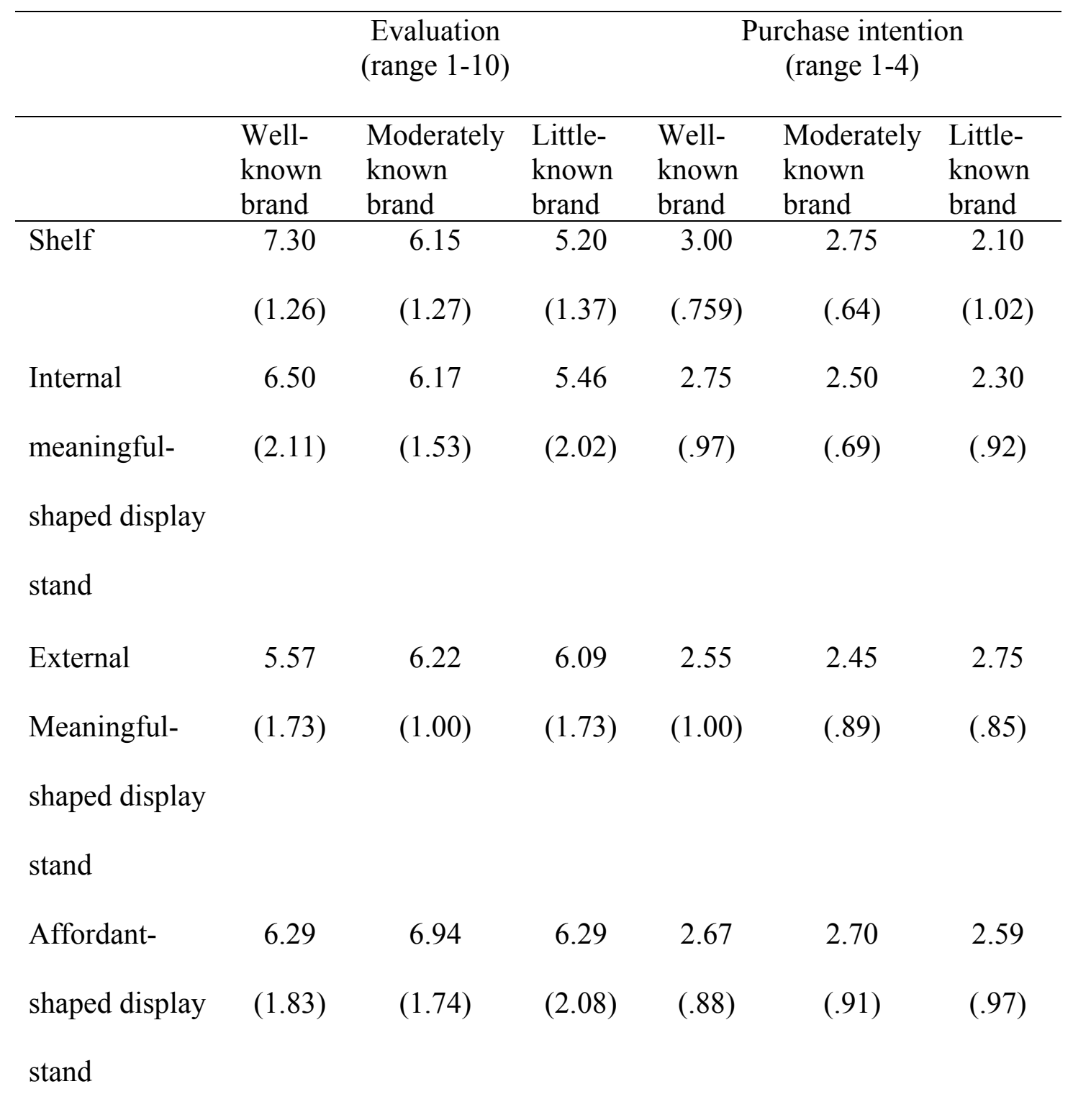


Figure caption.

Figure 1. Study 1 design: the indirect effect of product holder on purchase intention when product evaluation is the mediator. 


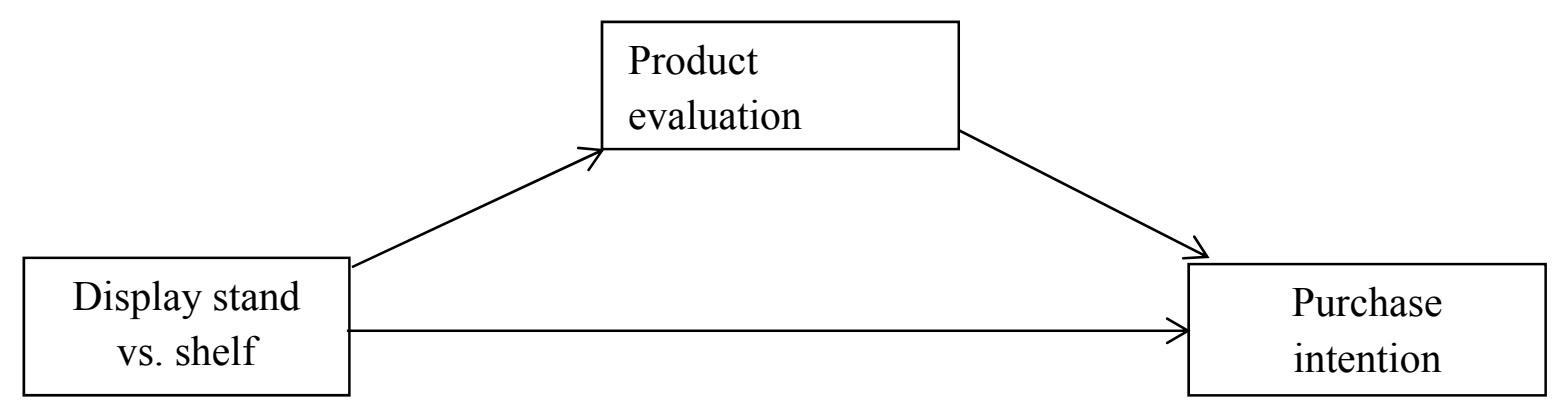

